\title{
POLICIES
}

\section{Interactions between health technology assessment, coverage, and regulatory processes: Emerging issues, goals, and opportunities}

\author{
Chris Henshall \\ University of York and Health Technology Assessment International
}

\author{
Logan Mardhani-Bayne \\ Health Technology Assessment International Secretariat
}

\author{
Katrine B. Frønsdal \\ Norwegian Knowledge Center for the Health Services
}

\author{
Marianne Klemp \\ University of Oslo and Norwegian Knowledge Center for the Health Services
}

\section{On behalf of the HTAi Policy Forum}

Background: The relationship between regulatory approval on the one hand and health technology assessment $(\mathrm{HTA})$ and coverage on the other is receiving growing attention. Those responsible for regulatory approval, HTA, and coverage have different missions and their information requirements reflect these. There is nonetheless an increasingly popular view that improved communication and coordination between these functions could allow them all to be undertaken effectively with a lower overall burden of evidence requirements, thus speeding patient access to new products and reducing unnecessary barriers to innovation. This study summarizes the main points emerging from a recent discussion of this topic at the HTAi Policy Forum.

Results and Conclusions: After considering the roles of the various bodies, stakeholder perspectives and some current practical initiatives, those present at the Forum meeting discussed possible goals and challenges for improved interactions-in general and at specific stages of the product development life cycle. Opportunities for progress were seen in: continuing the dialogue to promote understanding and interaction between the different bodies and stakeholders; working to align scientific advice for manufacturers on 
Henshall et al.

the design and data requirements of pre- and post-marketing evaluation of products

(specifically phase $2 / 3$ and phase 4 trials for drugs); and extending the current dialogue to

include discussion of product development to address unmet health needs.

Keywords: Health, Reimbursement, Insurance, Technology assessment, Biomedical

treatment outcome

\section{BACKGROUND AND AIMS}

The relationship between regulatory approval of drugs and medical devices on the one hand and health technology assessment (HTA) and coverage on the other is receiving growing attention from those responsible for these functions and from industry, governments, and patients (1). A range of factors has contributed to the increasing focus on this relationship, including (but not limited to) interests in: improving patient access to appropriate interventions; improving the efficiency of the development of new products; improving the evidence base for coverage decisions; and improving the transparency of those decisions and their rationale to the general public.

Interactions between regulatory, HTA, and coverage processes are at an early stage but may have important implications across and within health systems for patient care, innovation and system sustainability (3). These interactions were discussed by the Health Technology Assessment International (HTAi) Policy Forum at a meeting held from January 30, 2011 to February 1, 2011 in Windsor in the United Kingdom. The aim of this discussion was to identify goals, principles, challenges, and opportunities for improved interactions between regulatory, HTA, and coverage processes. This study summarizes the main points and suggestions arising from the discussions. While much of this study relates to drugs, many of its principles are considered to be relevant to other technologies, including medical devices, equipment, and diagnostics.

\section{HTAi Policy Forum}

HTAi is the international professional society for those doing and using HTA (8). HTAi runs the HTAi Policy Forum to provide an opportunity for leaders and management of public and private sector organizations to hold strategic discussions about issues of emerging international interest (10). The HTAi Policy Forum is comprised of fourteen for-profit organizational members from the drug, device and diagnostic industries, and fourteen not-for-profit organizational members representing HTA, coverage, insurance, and policy bodies. The HTAi Policy Forum meets to discuss topics selected by its members. Meetings observe the Chatham House Rule (2), and comprise a series of presentations, small group and roundtable discussions held over 2 days. This study presents the authors' view of the main points arising from the meeting and the areas of common thinking among participants. It has been informed by comments on drafts from those present, but it is not a consensus statement by Forum participants or their organizations. Supplementary Table 1 , which can be viewed online at www.journals.cambridge.org/thc2011017, lists attendees of the Windsor meeting.

\section{DEFINITIONS}

This study uses the following definitions:

- Regulatory approval refers to processes for determining market authorization for a health technology in a given jurisdiction

- Coverage refers to processes for determining which interventions will be provided, paid for or reimbursed in a health system. The nature of these processes varies across jurisdictions.

- Health technology assessment (HTA) aims to collect and analyze the information relevant to health decision makers using scientifically sound and transparent methods; a fuller definition of HTA can be found in the HTA Glossary (9). Those responsible for making coverage decisions are increasingly seeking input from HTA, but the relationship between HTA and coverage varies across jurisdictions.

In considering regulatory approval, HTA, and coverage, it is important to distinguish between the efficacy, effectiveness, relative efficacy, and relative effectiveness of a product or health intervention. This study uses definitions developed by the European Union High Level Pharmaceutical Forum (6):

- Efficacy is the extent to which an intervention does more good than harm under ideal circumstances.

- Relative efficacy is the extent to which an intervention does more good than harm, under ideal circumstances, compared with one or more alternative interventions.

- Effectiveness is the extent to which an intervention does more good than harm when provided under the usual circumstances of healthcare practice.

- Relative effectiveness is the extent to which an intervention does more good than harm compared with one or more intervention alternatives for achieving the desired results when provided under the usual circumstances of healthcare practice.

Relative effectiveness defined as above is broadly similar to the term comparative effectiveness being used extensively in the USA. 
Table 1. Regulatory approval, HTA, and coverage processes

\begin{tabular}{|c|c|c|c|}
\hline & Regulatory approval & $\begin{array}{l}\text { Health technology } \\
\text { assessment (HTA) }\end{array}$ & Coverage \\
\hline Legal authority & $\begin{array}{l}\text { Generally defined in national } \\
\text { public health legislation, with } \\
\text { regulatory bodies accountable to } \\
\text { the government in their } \\
\text { jurisdiction. }\end{array}$ & $\begin{array}{l}\text { HTA may be undertaken by a } \\
\text { group within and accountable to } \\
\text { a coverage body itself, and/or by } \\
\text { groups within and accountable } \\
\text { to a government department, } \\
\text { university, hospital, research } \\
\text { institute, or industry }\end{array}$ & $\begin{array}{l}\text { Generally defined within the rules } \\
\text { and regulations of the healthcare } \\
\text { system in which decisions are } \\
\text { being made, with coverage } \\
\text { bodies generally being } \\
\text { accountable to the healthcare } \\
\text { system within which they } \\
\text { operate. In some healthcare } \\
\text { systems, the role and } \\
\text { responsibilities of a coverage } \\
\text { decision-making body may be } \\
\text { defined in legislation and such a } \\
\text { body may be accountable to } \\
\text { government }\end{array}$ \\
\hline Role & $\begin{array}{l}\text { To decide on market authorization } \\
\text { for a product in the relevant } \\
\text { jurisdictions on the basis of } \\
\text { assessments of safety, quality, } \\
\text { efficacy, and benefit-risk profile. } \\
\text { Regulatory bodies often also } \\
\text { have a role to promote or } \\
\text { support the development of new } \\
\text { treatments addressing important } \\
\text { unmet health needs }\end{array}$ & $\begin{array}{l}\text { To provide the best evidence } \\
\text { available to inform decisions } \\
\text { about coverage, and decisions } \\
\text { about use by patients and } \\
\text { clinicians and/or tools to } \\
\text { support those decisions, such as } \\
\text { clinical practice guidelines }\end{array}$ & $\begin{array}{l}\text { To decide whether a product should } \\
\text { be covered, paid for, and/or } \\
\text { reimbursed within a particular } \\
\text { healthcare system, on the basis } \\
\text { of assessments of relative } \\
\text { effectiveness, cost, and in some } \\
\text { systems affordability and/or } \\
\text { value for money, given current } \\
\text { practice, funding, priorities, and } \\
\text { social values within the system }\end{array}$ \\
\hline Decision & $\begin{array}{l}\text { Does the product do more good } \\
\text { than harm for patients with } \\
\text { defined indications in this } \\
\text { jurisdiction? }\end{array}$ & $\begin{array}{l}\text { HTA seeks to support decisions on } \\
\text { whether an intervention offers } \\
\text { useful, appropriate, and } \\
\text { affordable benefits for patients } \\
\text { in a particular healthcare system }\end{array}$ & $\begin{array}{l}\text { Will the product offer useful, } \\
\text { appropriate (and affordable) } \\
\text { benefits for some or all eligible } \\
\text { patients in this healthcare } \\
\text { system? }\end{array}$ \\
\hline Evidence considered & $\begin{array}{l}\text { Pre-launch, typically evidence on } \\
\text { efficacy from randomized } \\
\text { controlled trials (RCTs), usually } \\
\text { placebo-controlled, although } \\
\text { active controls may be required } \\
\text { particularly when placebo } \\
\text { control would not be ethical. } \\
\text { Post-launch, evidence on relative } \\
\text { efficacy, effectiveness and/or } \\
\text { relative effectiveness may also } \\
\text { be considered when reviewing a } \\
\text { product's ongoing benefit-risk } \\
\text { profile. }\end{array}$ & $\begin{array}{l}\text { Such evidence on relative } \\
\text { effectiveness/efficacy (and costs } \\
\text { and opportunity costs across the } \\
\text { system) as can be assembled } \\
\text { from all relevant trials (of the } \\
\text { product and alternatives) with } \\
\text { placebo or active controls, and } \\
\text { where necessary other study } \\
\text { designs and/or analytic } \\
\text { techniques such as modeling }\end{array}$ & $\begin{array}{l}\text { Initially, such evidence on relative } \\
\text { effectiveness (and costs and } \\
\text { opportunity costs) as can be } \\
\text { assembled from all relevant trials } \\
\text { (of the product and alternatives) } \\
\text { with placebo or active controls, } \\
\text { and where necessary other study } \\
\text { designs and/or analytic } \\
\text { techniques. Coverage or ongoing } \\
\text { coverage may sometimes be } \\
\text { made conditional on the } \\
\text { collection and review of further } \\
\text { evidence post-launch or } \\
\text { initial/provisional coverage. } \\
\text { Evidence considered may or may } \\
\text { not be in the form of an HTA }\end{array}$ \\
\hline
\end{tabular}

\section{Regulatory Approval, Coverage, and HTA} Status and Roles of Different Bodies. Key differences between regulatory approval, HTA, and coverage decisions must be recognized in considering how to improve their interactions. Table 1 summarizes the key features of each, drawing on the study by Eichler et al. (3). Although these descriptions refer primarily to drugs, many of the principles also apply to devices. (See below for a discussion of differences between drugs, diagnostics, devices, and equipment.)
Pharmaceuticals, Diagnostics, Medical Devices, and Equipment. Arrangements for regulatory approval, HTA, and coverage differ for drugs, diagnostics, medical devices, and equipment.

Virtually all countries have legislation and regulatory bodies for pharmaceuticals. Most also have arrangements for diagnostics, medical devices, and equipment, although there is considerable variation between different classes of product and in how these are handled between countries, including variations in processes for the assessment and approval of 
diagnostic/drug combinations (as in "personalized medicines") or for hybrid technologies (e.g., implantable drug delivery systems).

The regulatory process for diagnostics, medical devices, and medical equipment typically focuses on product safety and function (e.g., reliably detecting specified biomarkers in the case of a diagnostic). The extent to which regulators require evidence of clinical benefit for patients typically depends on the level of risk to which patients are exposed, and for many products, trials to establish efficacy or clinical benefit are not required by regulators or undertaken by manufacturers.

International Coordination. Coordination between pharmaceutical regulators is well established internationally through the International Committee for Harmonisation (12) and in the European Union (EU) through either centralized review by the European Medicines Agency (EMA) or decentralized review led by an individual member state (4). There is substantial similarity in the information that regulatory bodies require from manufacturers. International coordination of the regulatory approval of diagnostics, medical devices, and medical equipment is less well developed, although discussions are currently in progress internationally (7) and within the EU (5).

There is no formal coordination among coverage bodies internationally. Some coverage and many HTA bodies participate in international platforms to discuss the development and use of HTA and other forms of analysis. The two primary such platforms are HTAi (8) and the International Society for Pharmacoeconomics and Outcomes Research (ISPOR) (14). Public sector HTA agencies also collaborate through the International Network of Agencies for HTA (INAHTA) (13), and (for government HTA bodies primarily in Europe) the EUnetHTA Joint Action project. These and earlier initiatives have worked to improve the coordination of evidence requirements and of assessments among HTA agencies. However, healthcare, financial, social, and political contexts vary significantly between jurisdictions, and the information requirements and decision criteria of HTA and coverage bodies around the world differ significantly (11).

\section{RESULTS}

\section{Interactions Among HTA, Coverage, and Regulatory Bodies: Current Position}

Drivers of Interest. Discussion at the Policy Forum identified several factors leading to increased interest in the relationship among regulatory, HTA, and coverage systems and decisions. This relationship has come under increasing scrutiny in recent years as a result of several factors, including:

- Increasing public and policy-maker awareness that some products approved by regulators may not be recommended by HTA bodies or approved by coverage bodies.
- Increasing use of HTA by coverage bodies, and increasing demands by HTA bodies for evidence beyond that required for regulatory approval, particularly evidence relating to the strength and relevance of clinical benefits.

- Increasing interest among regulators, HTA, and coverage bodies in post-marketing data collection, analysis, and review.

- Increasing interest in provisional or progressive decisions (i.e., cases in which decisions about coverage and/or product indications may be revised or expanded as additional evidence is generated throughout the product life cycle) in both the regulatory and coverage functions (15).

- An increasingly shared view that improved communicationand where appropriate coordination-between regulators, HTA, and coverage bodies and manufacturers could improve the efficiency of review processes and lower the overall burden of evidence requirements over the product life cycle, and thus enable faster patient access to useful products.

Interest in these issues has arisen primarily in the context of the regulatory approval and coverage of drugs, but many of the factors involved are relevant also to diagnostics, devices, and medical equipment.

Other Stakeholder Perspectives. Discussion at the Policy Forum also identified the need for interactions among regulatory, HTA, and coverage bodies to recognize the perspectives of other stakeholders:

- Patients - want the development of new treatments and rapid access to products that offer benefits they value at acceptable risk; want easy access to information about what is and is not available for their condition and why.

- Clinicians - want information on the real-world effectiveness and risks of products and freedom to offer patients what they believe is best for them.

- Governments - wish to ensure that their populations are protected from harmful products and have access to products that address important health needs; wish to ensure that healthcare systems meet health needs of the population and (in some contexts) offer value for money; those with healthcare industry $R \& D$ and/or manufacturing based in their country also wish to promote the success of those sectors.

- The general public (whether or not patients) - expects rapid access to improved new products while being protected from harm; tends to look for certainty and expects official bodies and healthcare systems to provide it and to be accountable, transparent, consistent, and efficient.

- Industry - seeks to develop and market safe, effective, and profitable products; needs to generate evidence to support regulatory and coverage approval and therefore has an interest in ensuring clarity and predictability in those evidence requirements over the product life cycle, and convergence where that is possible, to allow requirements to be met as efficiently as possible; recognizes that without progress in at least some of these areas, new product development will be increasingly difficult and costly. 
Current Initiatives to Improve Interactions. The Policy Forum received reports of various activities around the world aimed at improving interactions across regulatory, HTA and coverage processes. Regulatory, HTA, and/or coverage bodies are now working together internationally and in specific jurisdictions, in some cases simply to share information on procedures, requirements and plans, in others to align time frames and other logistical aspects of their review processes, and in others to align procedures for offering scientific advice to manufacturers. Whereas approaches and results vary considerably between initiatives, it appears that significant progress can be made in building understanding and trust and adapting processes, sometimes in highly challenging areas, if there is sufficient effort and high-level support and clarity about goals.

\section{Improving Interactions: Goals and Challenges}

Overall Goals, Principles, and Challenges. The following were identified at the Forum meeting as important overall goals of improved interactions among regulatory, HTA, and coverage bodies:

- To speed patient access to valuable products.

- To remove unnecessary barriers to successful development and appropriate market access for innovative products.

- To give manufacturers greater clarity about what evidence is required by which bodies and when.

- To improve alignment of the timing and logistics of processes where appropriate.

- To align methodological guidance and data requirements for establishing safety, efficacy, effectiveness, and relative efficacy and effectiveness in so far as necessary and possible, and to be clear why requirements differ when they do.

- To give patients and the public better understanding of the reasons for decisions by regulators and coverage bodies, especially where these differ.

Discussions also identified some important principles to underpin actions taken to achieve these goals:

- Regulatory, HTA, and coverage bodies should work together where possible and appropriate to maximize benefits for patients and the public.

- Patients, industry, and clinicians need to be actively engaged in discussions about regulatory, HTA and coverage processes; the wider public perspective also needs to be considered.

- All parties and stakeholders need to be clear and open with one another about their remits, goals, and interests.

- All parties need to accept that, while improvements in coordination should be actively sought, the missions of regulators and coverage bodies are different and some of their evidence requirements differ accordingly, and there are legitimate occasions (e.g., based on statute) when a product granted regulatory approval will not be covered in a particular healthcare system for some or all of its licensed indications.

The following emerged as potential challenges to be overcome:

- Lack of trust and understanding: There is insufficient understanding within regulatory, HTA, and coverage bodies and industry of respective purposes, remits, and processes, and a lack of understanding of these by other stakeholders. This may lead to unrealistic expectations about the extent of coordination and agreement that can be achieved.

- Organizational goals and culture: The goals and priorities of regulatory, HTA, and coverage bodies are different and they have different traditions, ways of working, and relations with stakeholders.

- Stakeholder involvement: There is a need to involve clinicians and patients in discussions about the relationship between regulatory, HTA, and coverage processes.

- Information concerns: There is concern in HTA and coverage bodies that industry may not disclose to them all relevant information about a product, while industry has concerns about the security of proprietary information if shared with HTA and coverage bodies. Legal constraints may limit information sharing between regulatory and other bodies.

\section{Specific Goals and Challenges Throughout the} Product Life Cycle. In addition to these general considerations, discussion also identified goals and challenges relevant to specific stages of the product life cycle, notably $R \& D$ investment decisions, design of pre-market evaluations, initial regulatory, HTA and coverage reviews, and post-market data collection and analysis. Table 2 summarizes the different goals and challenges identified at these life cycle stages. Much of the material in this and subsequent sections relates primarily to pharmaceuticals. The Forum meeting included discussion of devices and diagnostics, and saw the greatest opportunity for improved interactions between regulatory and HTA and coverage bodies following market approval for those types of products.

\section{Opportunities for Progress Toward These Goals}

Discussions at the Forum meeting suggested several activities to address challenges and make progress toward the goals proposed.

\section{Continue Dialogue to Promote Understanding} and Interaction.

- Build on initial national and international meetings between senior staff in regulatory and HTA and coverage bodies to promote understanding of, and trust in, each other's remits, methods, and processes.

- Build on wider initial national and international discussions between regulators, coverage bodies, HTA experts, and industry to 
Henshall et al.

Table 2. Goals and Challenges Along the Product Life Cycle

\begin{tabular}{|c|c|c|c|}
\hline & Readily achievable goals & More ambitious goals & Challenges and barriers \\
\hline $\begin{array}{l}\text { R\&D investment } \\
\text { decisions }\end{array}$ & $\begin{array}{l}\text { Joint discussions between } \\
\text { coverage bodies, regulators, } \\
\text { and industry about unmet } \\
\text { health needs and the } \\
\text { development and } \\
\text { reimbursement of products } \\
\text { to address them }\end{array}$ & $\begin{array}{l}\text { Include health ministries and public } \\
\text { biomedical research funders in these } \\
\text { discussions Improve incentive structures } \\
\text { for the development of new affordable } \\
\text { products for unmet health needs }\end{array}$ & $\begin{array}{l}\text { Identifying the right geographical } \\
\text { level to work at (i.e., country, } \\
\text { region, or international) } \\
\text { Identifying the right people to } \\
\text { engage from health ministries } \\
\text { and public research funders } \\
\text { Engaging clinicians, patients, } \\
\text { and the public more actively in } \\
\text { the discussions } \\
\text { Some coverage bodies may not see } \\
\text { discussions about new products } \\
\text { as a priority }\end{array}$ \\
\hline $\begin{array}{l}\text { Design of pre-market } \\
\text { evaluations (phase } \\
2 \text { and } 3 \text { trials) }\end{array}$ & $\begin{array}{l}\text { Coordinated or joint scientific } \\
\text { advice from regulatory and } \\
\text { coverage/HTA bodies for } \\
\text { industry on design of } \\
\text { pre-market evaluations } \\
\text { (phase } 2 \text { and } 3 \text { trials) of } \\
\text { specific products }\end{array}$ & $\begin{array}{l}\text { Coordinated or joint guidance from } \\
\text { regulatory and HTA and coverage bodies } \\
\text { for industry on data requirements for } \\
\text { products for specific conditions (e.g., } \\
\text { relevant outcome measures, comparators) } \\
\text { Joint guidance for industry from regulatory } \\
\text { and payer/HTA bodies on key general } \\
\text { aspects of trial design (to be developed in } \\
\text { parallel with guidance for specific } \\
\text { conditions, identifying the } \\
\text { methodological issues that are common } \\
\text { across conditions) } \\
\text { Harmonization of pre-marketing data } \\
\text { requirements }\end{array}$ & $\begin{array}{l}\text { Identifying the right geographical } \\
\text { level to work at (i.e., country, } \\
\text { region, or international) } \\
\text { Engaging clinicians and patients } \\
\text { more actively in the discussions } \\
\text { Progress on harmonization of } \\
\text { data requirements will depend } \\
\text { on progress on challenging } \\
\text { methodological issues around } \\
\text { comparative efficacy and } \\
\text { effectiveness, and on the relative } \\
\text { roles of regulatory and HTA and } \\
\text { coverage bodies in these areas }\end{array}$ \\
\hline $\begin{array}{l}\text { Initial reviews by } \\
\text { regulatory, HTA, } \\
\text { and coverage } \\
\text { bodies }\end{array}$ & $\begin{array}{l}\text { Coordination of } \\
\text { administrative procedures } \\
\text { of regulatory and HTA and } \\
\text { coverage bodies (e.g., } \\
\text { points and format of } \\
\text { submission) } \\
\text { Coordination of review and } \\
\text { decision time tables of } \\
\text { regulatory and HTA and } \\
\text { coverage bodies } \\
\text { Communication between } \\
\text { HTA, coverage, and } \\
\text { regulatory bodies before } \\
\text { market approval to allow } \\
\text { timely coverage decisions }\end{array}$ & $\begin{array}{l}\text { Sharing of industry data between regulatory } \\
\text { and HTA and coverage bodies }\end{array}$ & $\begin{array}{l}\text { HTA and coverage bodies will } \\
\text { need to guarantee that } \\
\text { proprietary data will be treated } \\
\text { in absolute confidence; and the } \\
\text { public and politicians will have } \\
\text { to accept that some data } \\
\text { underlying HTAs and coverage } \\
\text { decisions may not be publicly } \\
\text { available } \\
\text { Industry will need to accept that } \\
\text { HTA and coverage bodies want } \\
\text { access to all relevant data } \\
\text { submitted to regulatory bodies }\end{array}$ \\
\hline $\begin{array}{l}\text { Post-marketing data } \\
\text { collection, analysis, } \\
\text { and review }\end{array}$ & $\begin{array}{l}\text { Coordinated or joint scientific } \\
\text { advice from regulatory and } \\
\text { HTA and coverage bodies } \\
\text { for industry and public } \\
\text { sector research funders on } \\
\text { design of post-marketing } \\
\text { data collection for specific } \\
\text { products }\end{array}$ & $\begin{array}{l}\text { Coordinated or joint guidance from } \\
\text { regulatory and HTA and coverage bodies } \\
\text { for industry and public sector research } \\
\text { funders on design of post-marketing data } \\
\text { collection for specific conditions } \\
\text { Coordinated or joint guidance from } \\
\text { regulatory and HTA and coverage bodies } \\
\text { for industry and public sector research } \\
\text { funders on key methods for post- } \\
\text { marketing data collection and analysis } \\
\text { Harmonization of data requirements for, } \\
\text { and/or active collaborations on, } \\
\text { post-marketing surveillance between } \\
\text { regulators, HTA, and coverage bodies and } \\
\text { industry, to increase the value of the } \\
\text { information collected and avoid } \\
\text { unnecessary duplication }\end{array}$ & $\begin{array}{l}\text { Identifying the right geographical } \\
\text { level to work at (i.e., country, } \\
\text { region, or international); } \\
\text { Engaging clinicians and patients } \\
\text { actively in the discussions } \\
\text { Progress on harmonization of } \\
\text { data requirements will depend } \\
\text { on progress on methodological } \\
\text { issues around comparative } \\
\text { efficacy, effectiveness, and } \\
\text { safety, and on the relative roles } \\
\text { of regulatory and HTA and } \\
\text { coverage bodies in these areas }\end{array}$ \\
\hline
\end{tabular}


explore improved interactions between all parties; and increase the involvement of patients, clinicians, and the public in these discussions.

\section{Align Scientific Advice on Design of Pre- and Post-market Evaluations (Particularly Phase 2, 3, and 4 Studies for Pharmaceuticals).}

- Build on current work to develop joint scientific advice from regulators and HTA and/or coverage bodies for manufacturers on the design of pre-market evaluations (phase 2 and 3 studies) for specific products, expanding to more products, more jurisdictions and to phase 4 study design.

- Develop joint scientific advice from regulators and HTA and/or coverage bodies for industry on the design of pre- and postmarket evaluations (phase 2, 3, and 4 studies) for specific conditions, including such matters as appropriate comparators, outcome measures, study populations, and subgroups. These might be initiated in a particular region of the world, with the ultimate aim of developing internationally recognized guidance (allowing for the regional variations on specific issues such as preferred comparators) if possible.

- In parallel with the condition-specific advice above, develop joint scientific advice from regulators and HTA and/or coverage bodies for the general design of pre- and post-marketing evaluations (phase 2, 3, and 4 studies) so as to maximize the value of such studies to regulators, coverage bodies, clinicians and patients, covering such issues as:

- inclusion criteria

- subgroups

- patient cross-overs in trials

- general principles underlying choice of comparator

- primary and secondary endpoints, surrogate and patient/ clinically relevant outcome measures, quality of life measures

- relating trial populations to wider populations (e.g., to enhance power of phase 4 population studies)

- Industry, patients, and clinicians need to be actively involved in all of these developments

\section{Extend Dialog Better to Address Unmet Need.}

- Initiate discussions between manufacturers, public health and health system leaders, and regulatory and coverage bodies on unmet public health and health system needs and the development, assessment, and coverage of products to address them.

\section{CONCLUSIONS}

There is growing willingness to pursue dialogue on interactions. Resources in regulatory, HTA, and coverage bodies and in industry are limited, so effort must be well directed and focused on the areas of most importance. Discussions at the HTAi Policy Forum meeting have identified possible goals, opportunities, principles, and challenges for improved interactions. They have also identified national and international activities that could build on progress to date and help to address some of the challenges identified. Those working in and with the bodies concerned now have considerable opportunity to pursue these actions for the greater benefit of patients and society.

\section{SUPPLEMENTARY MATERIAL}

Supplementary Table 1

www.journals.cambridge.org/thc2011017

\section{CONTACT INFORMATION}

Chris Henshall, MA, PhD (consulting@chrishenshall. co.uk), Honorary Fellow, Centre for Health Economics, University of York, Heslington, York YO10 5DD, UK; Chair, HTAi Policy Forum, c/o HTAi Secretariat, Institute of Health Economics, 1200, 10405 Jasper Avenue, Edmonton, Alberta, Canada T5J 3N4

Logan Mardhani-Bayne, BA (Hons) (lmardhanibayne@ htai.org), Managing Director, Health Technology Assessment International Secretariat, 1200, 10405 Jasper Avenue, Edmonton, Alberta, Canada, T5J 3N4

Katrine B. Frønsdal, MSc, PhD (kbf@ nokc.no), Senior Researcher, Specialist Health Care Unit, Department of Evidence Based Practice, Norwegian Knowledge Center for the Health Services (NOKC), P.O. Box 7004 St. Olavsplass, N0130, Oslo, Norway

Marianne Klemp, MD, PhD (Marianne.Klemp@ kunnskapssenteret.no), Associate Professor, Department of Pharmacology, University of Oslo, 0316 Blindern, Oslo, Norway; Research Director, Department of Evidence Based Practice, Norwegian Knowledge Center for the Health Services, P.O. Box 7004 St. Olavsplass, N-0130, Oslo, Norway

\section{CONFLICT OF INTEREST}

Chris Henshall has received support for travel from HTAi for this work; he also has received consultancy fees from several medical companies for chairing Advisory Boards on specific technologies. Logan Mardhani-Bayne's institution has received support from HTAi for his travel to meetings in his role as Managing Director of the HTAi Secretariat, and grants from several medical companies to support HTA meetings. Katrine Frønsdal and Marianne Klemp report having received consulting fees from the HTAi Policy Forum for their institution (NOKC), which houses the scientific secretariat for the HTAi Policy Forum.

\section{REFERENCES}

1. Breckenridge A, Woods K, Walley T. Medicines regulation and health technology assessment. Clin Pharmacol Ther. 2010;87: 152-154. 
2. Chatham House. http://www.chathamhouse.org.uk (accessed March 2011).

3. Eichler H, Bloechl-Daum B, Abadie E, et al. Relative efficacy of drugs: An emerging issue between regulatory agencies and third-party payers. Nat Rev Drug Discov. 2010;9: 277-291.

4. European Medicines Agency (EMA). http://www.ema. europa.eu (accessed March 2011).

5. European Union Commission's Directives for Medical devices. http://ec.europa.eu/consumers/sectors/medical-devices (accessed March 2011).

6. European Union High Level Pharmaceutical Forum. High level pharmaceutical forum 2005-2008 final report. Core principles on relative effectiveness. http://ec.europa.eu/ pharmaforum/docs/ev_20081002_frep_en.pdf (accessed March 2011).

7. Global Harmonization Task Force (GHFT). http://www. ghtf.org (accessed March 2011).

8. Health Technology Assessment International (HTAi). http:// www.htai.org (accessed March 2011)

9. Health Technology Assessment International (HTAi) and the International Network of Agencies for Health Technology Assess- ment (INAHTA). HTA glossary. http://www.htaglossary.net (accessed March 2011).

10. Health Technology Assessment International (HTAi). Policy forum. http://www.htai.org/index.php?id=643 (accessed March 2011).

11. Hutton J, Trueman P, Facey K. Harmonisation of evidence requirements for health technology assessment in reimbursement decision making. Int J Technol Assess Health Care. 2008;24:511-517.

12. International Conference on Harmonisation of Technical Requirements for Registration of Pharmaceuticals for Human Use (ICH). http://www.ich.org (accessed March 2011).

13. International Network of Agencies for Health Technology Assessment (INAHTA). http://www.inahta.org (accessed March 2011).

14. International Society for Pharmacoeconomics and Outcomes Research (ISPOR). http://www.ispor.org (accessed March 2011).

15. Progressive Licensing Project, Health Canada. http://www.hcsc.gc.ca/dhp-mps/homologation-licensing/plfs_hpfd-eng.php (accessed March 2011). 